\title{
Load-Bearing Capacity Modelling and Testing of Single- Stranded Wire Rope
}

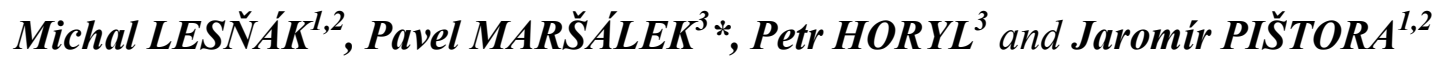

Authors' affiliations and addresses:

${ }^{1}$ Nanotechnology Centre, VŠB - Technical University of Ostrava, 17. listopadu 2172/15, 70800 Ostrava, Czech Republic

${ }^{2}$ Modelling for Nanotechnologies Lab, VŠB Technical University of Ostrava, 17. listopadu 2172/15, 70800 Ostrava, Czech Republic e-mail: michal.lesnak@vsb.cz e-mail: jaromir.pistora@vsb.cz

${ }^{3}$ Department of Applied Mechanics, Faculty of Mechanical Engineering, VŠB - Technical University of Ostrava, 17. listopadu 2172/15,

70800 Ostrava, Czech Republic

e-mail: pavel.marsalek@vsb.cz

e-mail: petr.horyl@vsb.cz

*Correspondence:

Pavel Maršálek, Department of Applied

Mechanics, Faculty of Mechanical Engineering,

VŠB - Technical University of Ostrava, 17.

listopadu 2172/15, 70800 Ostrava, Czech

Republic

tel: +420 597324351

e-mail: pavel.marsalek@vsb.cz

Funding information:

The Technology Agency of the Czech Republic TN01000024 National Competence, Center-

Cybernetics and Artificial Intelligence Structural Funds of the European Union within the project Innovative and additive manufacturing technology - new technological solutions for 3D printing of metals and composite materials, CZ.02.1.01/0.0/0.0/17 049/0008407

European Regional Development Fund in the IT4Innovations national supercomputing center path to exascale project, project number EF16 013/0001791 within the Operationa Programme Research, Development and Education.

\section{Acknowledgment:}

This work was supported by The Ministry of Education, Youth and Sports of the Czech Republic from the Specific Research Project SP2020/23

How to cite this article:

Lesňák, M., Maršálek, P., Horyl, P. and Pištora, J. (2020). Load-Bearing Capacity Modelling and Testing of Single-Stranded Wire Rope. Acta Montanistica Slovaca, Volume 25 (2), 192-200

DOI:

https://doi.org/10.46544/AMS.v25i2.6

\begin{abstract}
The load-bearing capacity of the wire rope is an extremely important factor for the precise rope design. This value mainly depends on the rope cross-section and the strength class. The nominal value of the load-bearing capacity can be found in the standards. However, this value is on the side of safety. For new rope constructions or improvements in production technology, it is suitable to determine the real value of load-bearing capacity. In this paper, we present two approaches, how to determine the real value of the load-bearing capacity related to the single-stranded wire rope. The first approach is based on a simplified experiment using a tensile test. This phase of the research is divided into two separate experiments. The first experiment is focused on tests of individual wires forming the rope. The second experiment is designed to test the entire wire rope.

Finally, the second approach uses the finite element method to create a computer model is presented. Since the rope tensile test is a strongly non-linear task, the solver LS-DYNA with an explicit time integration technique is used for simulation of the experiment. The results from both presented approaches are compared

With the nominal value. Designed experiment for testing the whole rope and computer modeling method is created based on the practical requirements from industry, and the obtained results will be reflected in the design of new types of wire ropes.
\end{abstract}

\section{Keywords}

wire, rope, single-stranded, load-bearing capacity, tensile test, fem, ls-dyna, explicit 


\section{Introduction}

The wire ropes are important technical elements in transport, construction, raw material mining, etc. (Straka et al., 2018). The ropes are made of patented steel wire of higher strength, which guarantees a high load-bearing capacity of the rope, relatively small weight, and sufficient flexibility. In particular, their high strength, which allows the construction of small diameter wires and low weight, meets required properties (especially stiffness and load-bearing capacity). During operation, many negative phenomena affect the ropes, which decrease their service life (Costello, 1997; and Ivanco, Kmet and Fedorko, 2016). A detailed analysis of the technical risk of steel wire ropes showed two main factors that most affect its reliability.

The first main factor is mechanical rope wear and corrosion. Especially the corrosion of internal wires (Molnar et al., 2017), which cannot be detected during visual inspections, is particularly dangerous. Damaged or corroded ropes, whose load-bearing capacity is under the prescribed limits, must be discarded immediately. In our former papers related to steel ropes, we focused on the inspection of magnetic field analysis around magnetized ropes with mechanical defects (Pistora et al., 2019). The non-reciprocity of magneto-optical (MO)surface plasmon resonance (SPR) reflection response observed by polarity change of the external magnetic field has been studied for sensor applications aimed at magnetic defectoscopy (Pistora et al., 2010; Vlcek et al., 2013).

The second main factor is the load-bearing capacity, which can be determined by experiment (Utting and Jones, 1987) or calculation. Using the theory of elasticity and strength, many authors have taken an analytical calculation approach to give this relationship between rope geometry and load-bearing capacity (Velinsky, 1985; Ghoreishi et al., 2007; Usabiaga and Pagalday, 2008). However, during the last decade, the deployment of the computer modeling method has been intensively studied (Nawrocki and Labrosse, 2000; Jiang, Henshall and Walton, 2000; Stanova et al., 2011; Yu et al., 2014; Fontanari, Benedetti and Monelli, 2015; Foti and di Roseto, 2016). The computer modeling method allows taking into account all important influences during the tensile test of wire ropes. In (Wang et al., 2015), the authors described a parametric computer model of the wire ropes for fast indeterminate contact analysis statically and dynamically. The local model of the wire rope has been implemented. The aims of the local model are to link the global quantities, namely tension and rope curvature, to local quantities that govern the fatigue damage at the wire level (Bussolati et al., 2018). The slipping and crushing behaviors of a steel wire rope during a tensile test using a curve-type clamping mechanism to realize safe and reliable clamping during safety testing have been studied (Song et al., 2019). The experimental results show that the improved clamping mechanism can effectively clamp the wire rope for tensile testing and meet test requirements. The breaking failure characteristics of hoist ropes with different wear scars were investigated by the breaking tensile test (Chang et al., 2019). The finite element method was used to simulate the mechanical properties of the wear-out strands subjected to tensile load. Results show that the severe plastic deformation and obvious temperature rise occur in the wear scar region. The wear-out outer wires fracture earlier than the internal wires, and the wires with irregular wear scar always fracture along the sliding wear direction at the location with the maximum wear depth.

In the frame industrial practice, the application of single-stranded wire rope is often used. For this reason, the modeling and experimental testing of the load-bearing capacity related is very important. The authors of the article have extensive experience with modeling load-bearing capacity of steel arch yielding supports (Horyl, Snuparek nad Marsalek, 2014; Horyl et al., 2016, 2017, 2019; Marsalek and Horyl, 2017).
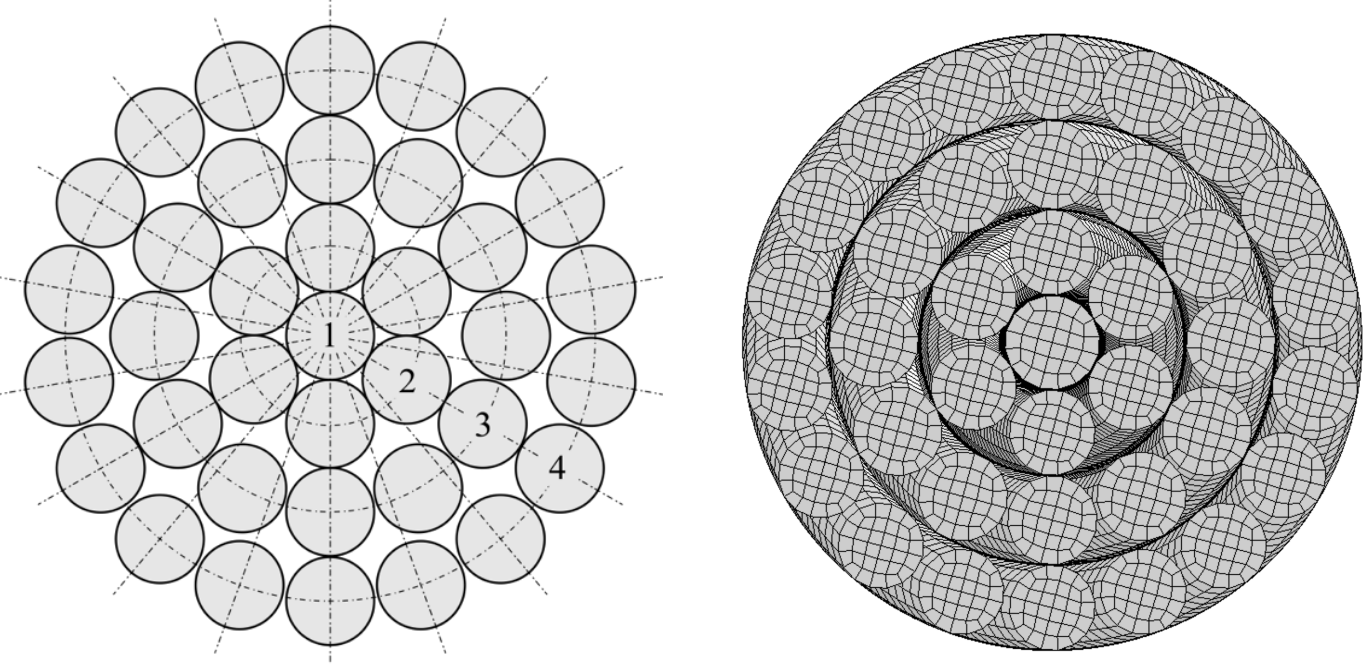

Fig. 1. Schematic diagram of single-stranded wire rope $1 \times 37$ (left) and finite-element mesh (right). 
The aim of work is to create a simple experiment determining the real value of the load-bearing capacity of the wire rope. Using this experiment, a computer model describing the failure of steel ropes is created and validated. For these purposes, a single-strand steel wire rope - labeled $1 \times 37$ is chosen. Fig. 1 gives the cross-section of this rope. The rope is made up of 37 wires with the construction of $1+6+12+18$ wires in individual layers. The rope with an outer diameter of $d=8.00 \mathrm{~mm}$ is used during the tests with declared rope strength class $\sigma_{r}=1,570 \mathrm{MPa}$. The rope wires have been galvanized. The nominal rope cross-section is $S_{n}=37.30 \mathrm{~mm}^{2}$. The nominal load-bearing capacity of the rope is $F_{n}=51.50 \mathrm{kN}$ declared by a manufacturer. The rope complies with Standard (CSN EN 12385-4, 2008) and (Standard DIN 3054, 1972). The measured wire diameters are given in Tab. 1. The real rope cross-section $S_{r}=39.77 \mathrm{~mm}^{2}$ is calculated from the measured diameters of each wire.

\begin{tabular}{l|cccc}
\multicolumn{7}{c}{ Tab. 1. Wire diameters for each rope layer } \\
\hline Rope layer i [-] & 1 (inner layer) & 2 & 3 & 4 (outer layer) \\
\hline Wire diameter di $[\mathrm{mm}]$ & 1.27 & 1.15 & 1.20 & 1.15 \\
\hline
\end{tabular}

\section{Material and Methods}

\section{Experiment}

This phase of the research was divided into two separate experiments that were conducted using a tensile test on the TESTOMETRIC M500-50CT. The first experiment was focused on tests of individual wires forming the rope. The aim was to obtain the wire behavior needed for the computer modeling of the entire rope. Another goal is to calculate the load-bearing capacity of the rope $F_{w}$ using the load-bearing capacity of individual rope wires $F_{w i}$. The wire tensile test results are given in Fig. 2. and measured load-bearing capacities for individual wires in the rope layer are summarized in Tab. 2. The load-bearing capacity calculated from individual wire measurement $F_{w}=66.67 \mathrm{kN}$ is determined as the sum of the measured load-bearing capacities of individual wires (see Tab. 2).

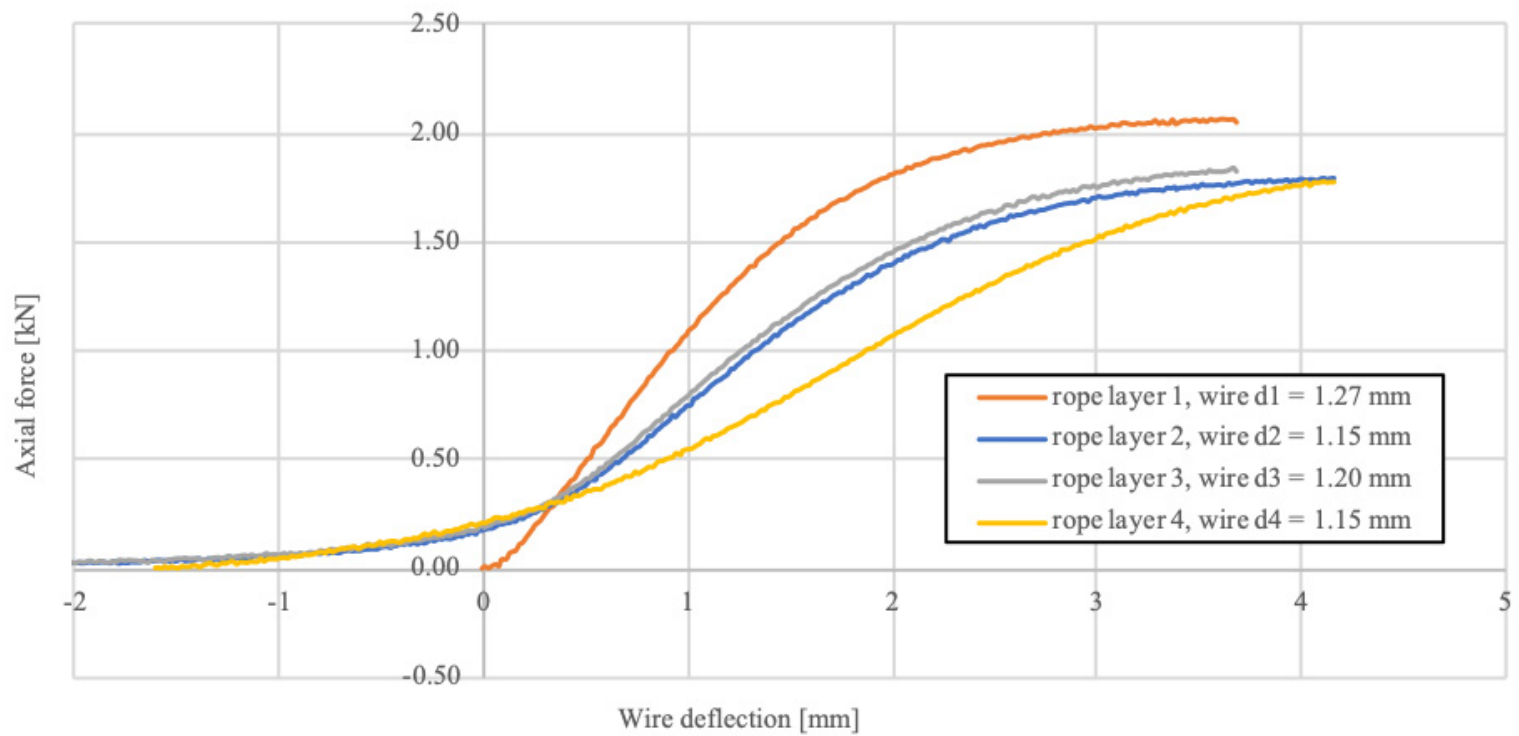

Fig. 2. Tensile test of individual wires in the rope layer.

Tab. 2. The measured load-bearing capacity of individual wires in the rope layer

\begin{tabular}{l|ccc}
\hline Rope layer i [-] & 1 (inner layer) & 2 & 3 \\
\hline $\begin{array}{l}\text { The measured load-bearing capacity of wire Fwi } \\
{[\mathrm{kN}]}\end{array}$ & 2.05 & 1.83 & 1.80 \\
\hline
\end{tabular}

The second experiment was designed to test the entire wire rope (the distance between the jaws was $l=150 \mathrm{~mm}$ ). During rope tests, it was found that the testing samples were poorly attached to the machine's jaws. The inner wires were not sufficiently pressed together (not fully gripped) and then pulled the axial forces were not transferred to the individual rope layers (especially to the inner layer). Thus, only the outer rope layers experienced excess loading. When more axial force was applied with the jaws, the wires near the grip cracked, and the core of the rope was not stressed. For this reason, both ends of the test sample were welded. The measurements were repeated using samples with the ends welded. The experiments confirmed 
the expediency of this approach. The results of these experiments are shown in Fig. 3. The load-bearing capacities of the welded samples obtained from the tests are listed in Tab. 3.

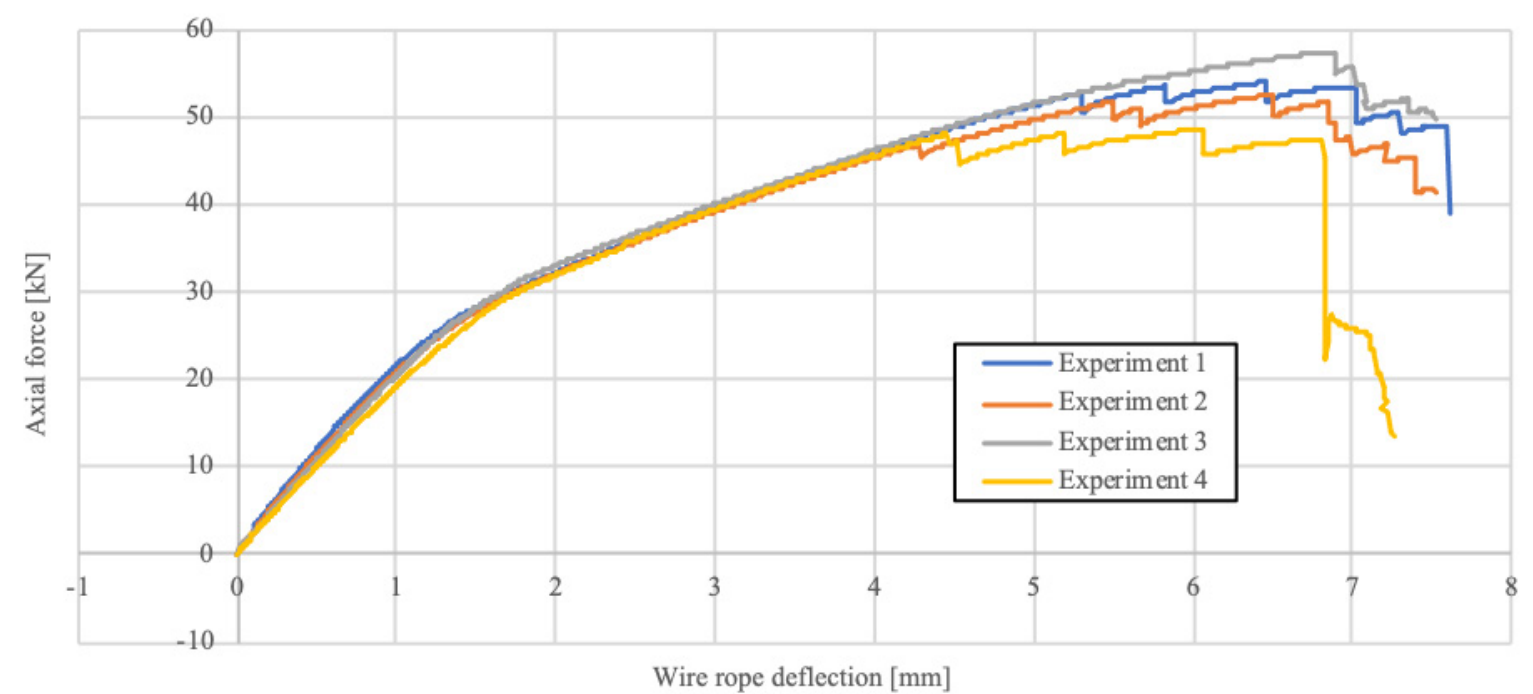

Fig. 3. Tensile test of the entire rope.

Tab. 3. The measured load-bearing capacity of the entire rope

\begin{tabular}{l|ccc}
\hline Experiment & 1 & 2 & 3 \\
\hline $\begin{array}{l}\text { Measure the load-bearing capacity of rope } F_{r} \\
{[\mathrm{kN}]}\end{array}$ & 54.00 & 52.55 & 57.45 \\
\hline
\end{tabular}

\section{Computer modeling}

The finite element method was used to create a computer model for the experiments described above. The LS-DYNA R7.1 solver was applied to solve the tasks (Judge et al., 2012). In the initial research, test tasks were carried out to make the computer model more accurate. Here, a quasi-static implicit solution of the spatial task was considered with all kinds of nonlinearities (material model, frictional contact between all wires, large displacements, and deformations). The static solution converged to overcome frictional forces between layers. Consequently, the divergence has been registered, and it was not possible to successfully complete the task even when the stabilization has been applied (in the form of damping and numerical stabilization). Subsequently, the task was formulated as an implicit dynamic. Unfortunately, this approach did not lead to success. Therefore, the solution of the problem was chosen to be explicitly dynamic (Cech, Horyl and Marsalek, 2016; Marsalek et al., 2017; Klemenc et al., 2017) based on the fact that after overcoming the frictional forces between the wires, there is a dynamic realignment of the wires.

Geometric Model. The geometric model for the wire rope has been produced by pulling the cross-sections of the individual wires along the helix (50 $\mathrm{mm}$ gradient per one turn). The rope cut geometry was obtained from (Standard CSN 02 4313, 2004); and wire diameters are specified in Tab. 1. Wires inside the rope touch tangentially. There is no penetration or looseness. Initial geometry is ideal, without the curvature effect caused by manufacturing technology. The initial state is characterized by zero stress in all the rope wires. The model geometry can be considered consistent with the test sample.

Finite Element Mesh. The finite element mesh was created by a controlled generation using SW Altair Hypermesh. Element drag along a curved wire axis was used to establish a mapped mesh consisting of 8 node hexahedral elements with full integration. The element edge is between $0.20 \mathrm{~mm}$ and $0.25 \mathrm{~mm}$. Mesh fineness was chosen concerning the task's time step, and its statistics are specified in Tab. 4. Mass scaling was used to adjust the time step to $\Delta t=2.80 \cdot 10^{-5} \mathrm{~ms}$.

Tab. 4. Finite element mesh statistics

\begin{tabular}{l|c}
\multicolumn{2}{c}{ Tab. 4. Finite element mesh statistics } \\
\hline Nodes & 860,000 \\
\hline Elements & 630,000 \\
\hline
\end{tabular}

Material Model. The same material model was chosen for all wires. It is high-strength steel, which is further strengthened by the wire production technology. Based on the experiments, an elastoplastic material model with kinematic hardening (*MAT_003) was preferred. The material constants given in Tab. 5 were subtracted based on the averaged results of the first single-wire experiment (see Section 1). There are two variants 
of calculation, where the influence of the defects defined by the failure strain fs is analyzed. The failure strain is prescribed for rope volume in the distance $e=20 \mathrm{~mm}$ from the jaws.

Tab. 5. Material model parameters

\begin{tabular}{l|c}
\hline Material model parameter & Value \\
\hline Young's modulus $E[\mathrm{GPa}]$ & 200.0 \\
Poisson ratio $\mu[-]$ & 0.300 \\
Yielding Stress $\sigma_{y}[\mathrm{GPa}]$ & 1.300 \\
Tangent modulus $E_{t}[\mathrm{GPa}]$ & 22.20 \\
Density $\rho\left[\mathrm{kg} \mathrm{m}^{-3}\right]$ & 7,800 \\
Failure $\operatorname{strain} f_{s}[-]$ & 0.025 and 0.031 \\
\hline
\end{tabular}

Boundary and Initial Conditions. The definition of the computer model's marginal conditions is chosen concerning the second experiment (tensile test of the entire rope). The effect of compressing the ends of the rope by the grips is not considered. One end of the rope is fixed. The other end is rotated during blocking and feeding. Only the jaw velocity $v=5.00 \mathrm{~ms}^{-1}$ in the pull direction is prescribed.

A robust *CONTACT_AUTOMATIC_SINGLE_SURFACE friction contact with a Coulomb friction model was used for the numerical description of the contacts between the wires (Benson and Hallquist, 1990). This formulation automatically seeks out contact between the wire surfaces. The friction coefficient chosen to describe the magnitude of the frictional forces was $f=0.10$. Several values of the friction coefficient $(f=0.10$ to 0.50 ) were tested with no significant effect on the result (Sun et al., 2005; Chen et al., 2017).

\section{Results}

Many calculations modeling real tensile tests were realized. The results correspond to real experiments and are shown in Fig. 3 (comparison with Fig. 4). To compare the data obtained, the calculated rope shift is normalized by $u=0.30 \mathrm{~mm}$. This shift corresponds to the wires limiting during the tensile test simulation, which arises due to the idealization of the rope's geometric model.

Calculated dependences - green corresponding to failure strain $f_{s}=0.031$ and light blue corresponding to failure strain $f_{s}=0.025$ - are compared with measured data (remaining curves). When using explicit time integration to calculate the load-bearing capacity, the noise is generated as a result of discretization and the absence of damping. In fact, during the tensile test, the jaws' velocity is very low, therefore the response given in Fig. 3 is smooth. It is necessary to use a low pass filter to determine the load-bearing capacity of the entire rope, as it eliminates the effect of high frequencies on the calculated response. Based on previous experience, the SAE J211-600 Hz two-pole filter is applied. The calculated load-bearing capacities for both values of entire rope failure strain $\left(f_{s}=0.025\right.$ and $\left.f_{s}=0.031\right)$ are given in Tab. 6. The wire break pattern (Fig. 5) copies the actual experiment.

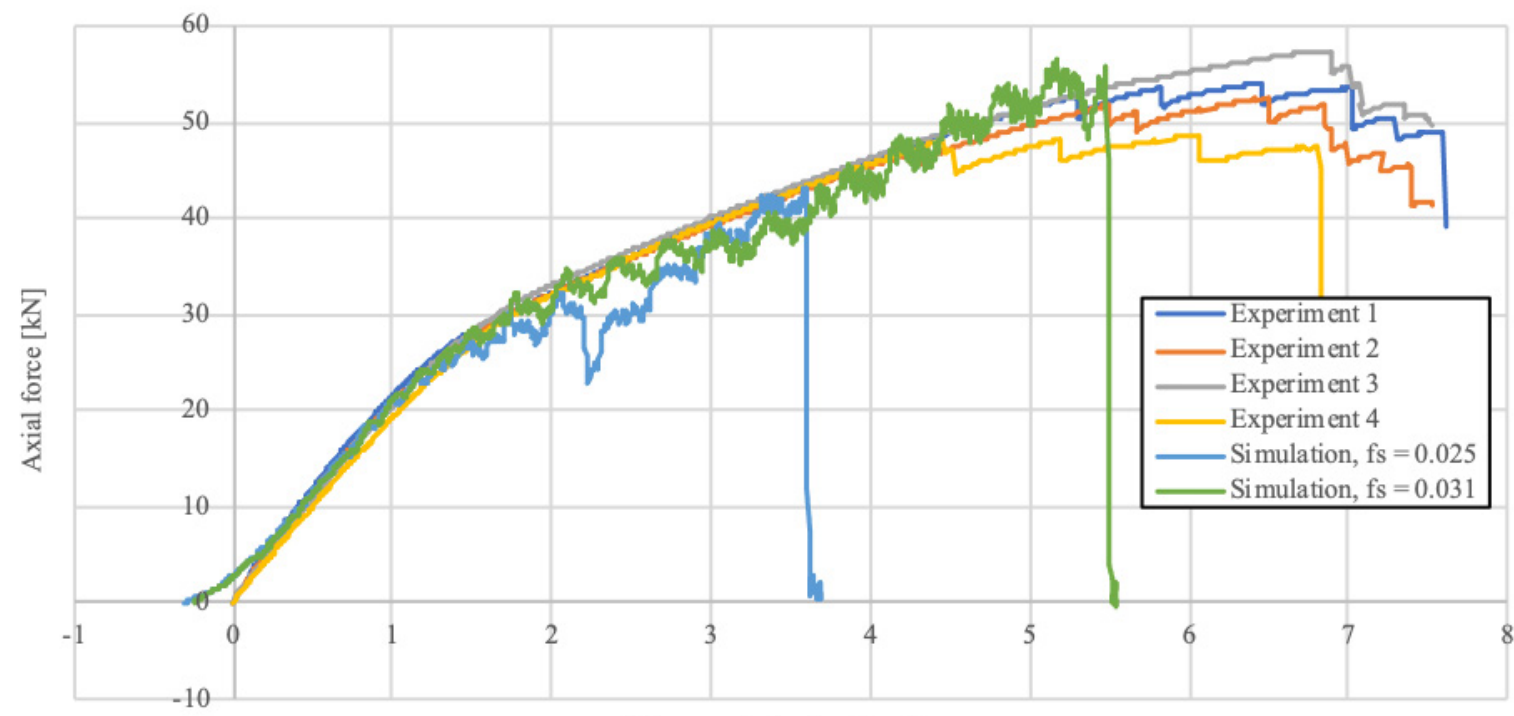

Wire rope deflection $[\mathrm{mm}]$

Fig. 4. Comparison of calculated results with measured data for the entire rope. 


\begin{tabular}{l|cc}
\multicolumn{4}{c}{ Tab. 6. Rope load capacity obtained by the computer model } \\
\hline Failure strain $f_{s}[-]$ & 0.025 & 0.031 \\
\hline Load-bearing capacity $F_{c}[\mathrm{kN}](\mathrm{SAE} 600 \mathrm{~Hz}$ Filter) & 43.93 & 55.79 \\
\hline
\end{tabular}

The load-bearing capacity of the rope $\left(F_{c}=55.79 \mathrm{kN}\right)$ determined by the computer modeling method (Tab. 6) is very sensitive to the failure strain (plastic deformation) - as is the measured load-bearing capacity of the rope (Tab. 3) specified by the tensile test.

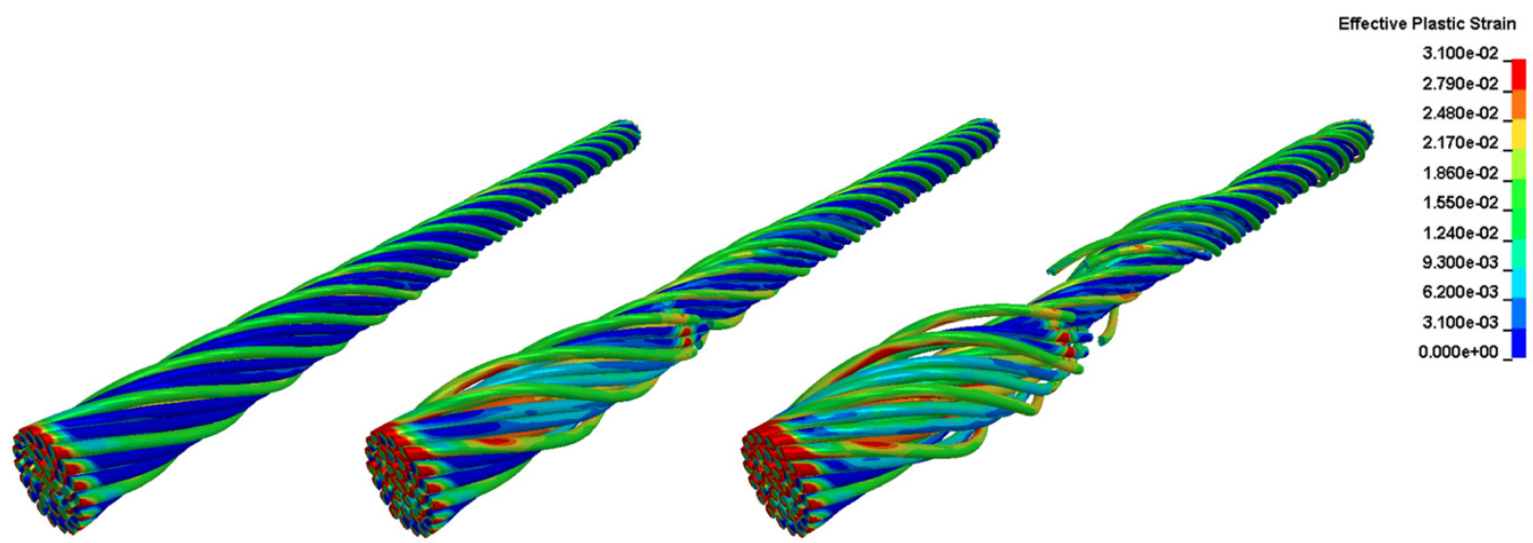

Fig. 5. Animation of rope break for failure strain $f_{s}=0.031$ corresponds to calculated load-bearing capacity $F_{c}=55.79 \mathrm{kN}$.

\section{Discussion}

The load-bearing capacity of wire ropes presents an important parameter for wire design. During the study of data from both presented experiments, we create a computer model using the finite element method that determines the load-bearing capacity with sufficient accuracy.

To determine the real load-bearing capacity value using the computer modeling method, the creation of an accurate geometric model is necessary. It is necessary to note that only from a detailed comparison of the nominal rope cross-section is $S_{n}=37.30 \mathrm{~mm}^{2}$ with the real rope cross-section $S_{r}=39.77 \mathrm{~mm}^{2}$. The difference between values is $6.6 \%$, see Tab. 1 .

However, another key factor is the material model and the determination of the material constants. Based on the performed calculations, it was found that the load-bearing capacity is very sensitive to the failure strain value $f_{s}$ and the chosen method of response filtering.
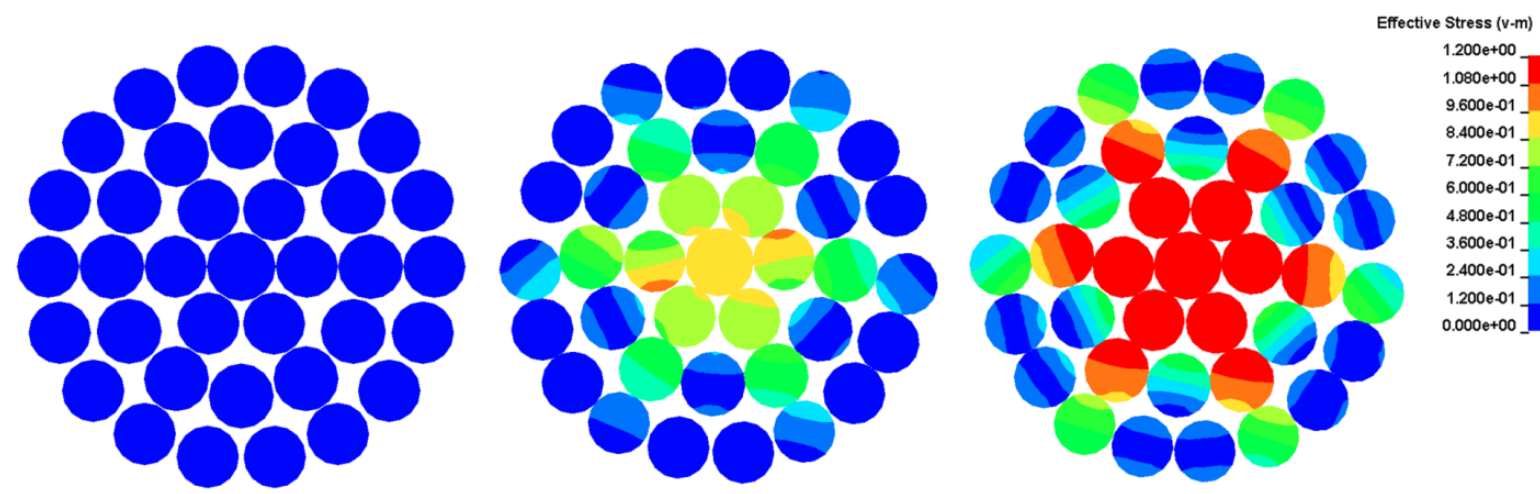

Fig. 6. Cross-section of tested rope sample for axial force $F=0 \mathrm{kN}, 10 \mathrm{kN}$, and $20 \mathrm{kN}$ - von Mises stress. 

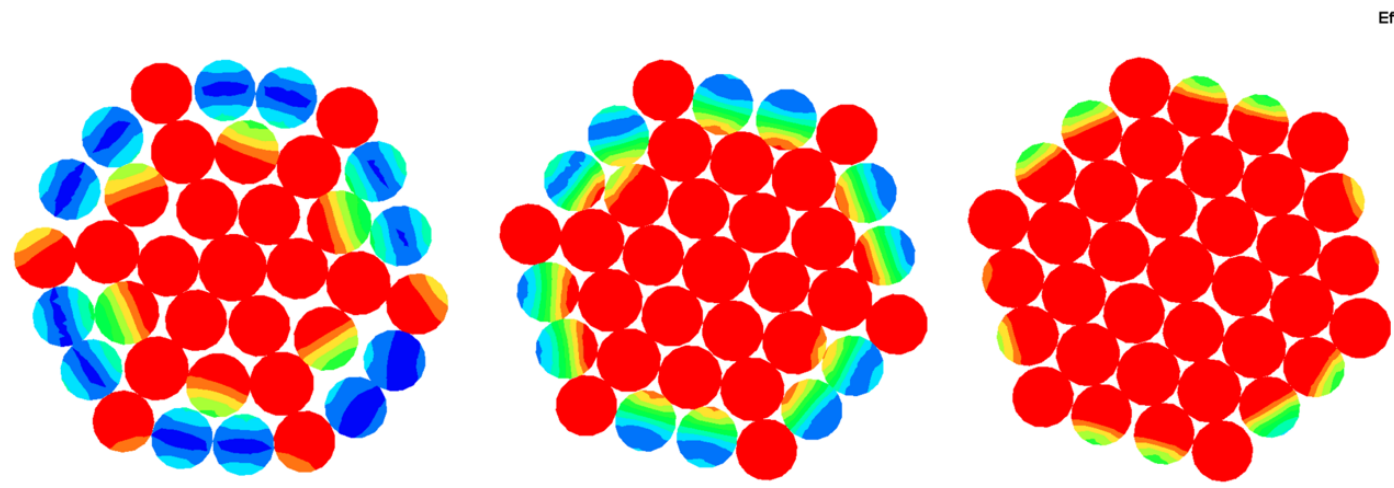

Effective Stress (v-m)

Fig. 7. Cross-section of tested rope sample for axial $F=30 \mathrm{kN}, 40 \mathrm{kN}$, and $50 \mathrm{kN}-$ von Mises stress.

In Fig. 6 and Fig. 7, a cross-section of the analyzed wire rope during loading is illustrated. Fig. 6 and Fig. 7 show a noticeable effect of significant load on the internal wires, where plastic deformation occurs from axial force $F=12.50 \mathrm{kN}$ have been observed. In addition, the overall deformation of the rope under load is clearly visible. Using a stress distribution obtained by the presented computer model, the ideal rope cross-section (including the shape of individual wires) can be designed.

Using linear regression of the data measured, the stiffness of the entire rope $k_{c}$ in the length $l=150 \mathrm{~mm}$ was specified. The stiffness of the entire rope $k_{c}$ is 2.6 times smaller than the stiffness of the solid steel bar of cross-section $S_{r}=39.77 \mathrm{~mm}^{2}$ with equivalent length, see Tab. 7. This rope property is very important for computer modeling of large structures containing wire ropes (mining towers, suspension bridges, etc.).

\begin{tabular}{l|c}
\multicolumn{2}{c}{ Tab. 7. Comparison of entire rope stiffness } \\
\hline Parameter & Value \\
\hline Stiffness of the entire rope $k_{c}[\mathrm{kN} / \mathrm{mm}]$ & 20.40 \\
\hline Stiffness of a solid steel bar $k_{b}[\mathrm{kN} / \mathrm{mm}]$ & 53.03 \\
\hline
\end{tabular}

\section{Conclusion}

The safety factor of the wire rope is given by the ratio between the load-bearing capacity of the rope and its maximum design load. For wire ropes that have not been subjected to the required tests, the nominal load-bearing capacity $F_{n}$ is used. The nominal value is on the safe side, as well as the nominal cross-section. If we would like to specify the real value of the load-bearing capacity, it is necessary to experiment with the subjected rope or its wires. In this work, a simple experiment was designed, and a corresponding computer model was created, which can be used to accurately determine the real value of the load-bearing capacity of the wire rope.

In the first part of the work, the individual wires were tested, followed by testing the entire rope. For these purposes, a single-strand steel wire - labeled 1x37 was chosen. Steel rope is made up of 37 wires with the construction of $1+6+12+18$ wires in individual layers. Ropes with an outer diameter of $\mathrm{d}=8.00 \mathrm{~mm}$ were used during the tests with declared rope strength $\sigma_{r}=1,570 \mathrm{MPa}$. Based on the performed research work, three values of load-bearing capacity were determined (Tab. 8).

Tab. 8. Comparison of obtained load-bearing capacity values

\begin{tabular}{l|c}
\hline Experiment & Value \\
\hline Nominal load-bearing capacity $F_{n}[\mathrm{kN}]$ (Standard CSN 024313,2004$)$ & 51.50 \\
\hline Load-bearing capacity calculated from each wire measurement $F_{w}[\mathrm{kN}]$ & 66.67 \\
\hline Load-bearing capacity calculated from the entire rope measurement $F_{r}[\mathrm{kN}]$ & 53.16 \\
\hline Load-bearing capacity obtained from the presented computer model $F_{c}[\mathrm{kN}]$ & 55.79 \\
\hline
\end{tabular}

In the first phase, the load-bearing capacity calculated from individual wire measurement $F_{w}=66.67 \mathrm{kN}$ is determined as the sum of the measured load-bearing capacities of individual wires (see Tab. 2). This estimated value is only theoretical. The load-bearing capacity calculated from individual wire according to the result of the experiment is about $29.5 \%$ higher than the nominal value $F_{n}=51.50 \mathrm{kN}$. The use of this method is not suitable due to the uneven distribution of wire due to their different stiffness. The result does not appear to be accurate. To determine the real load-bearing capacity, it is necessary to use the testing of the entire wire rope. This was performed in the second phase of the work. Load-bearing capacity calculated from the entire rope measurement $F_{r}=53.16 \mathrm{kN}$ is determined by testing the wire rope in the length $l=150 \mathrm{~mm}$. The value given 
in Tab. 8 is calculated using the arithmetic mean of testing 4 samples, see Tab. 3. According to the results of the entire rope experiment, this value is $3.2 \%$ higher than the nominal value. The results obtained with this procedure show high accuracy of the measurement. The last phase describes the load-bearing capacity obtained from the presented computer model $F_{c}=55.79 \mathrm{kN}$, which was validated based on the experiment. This value is $8.3 \%$ higher than the nominal value.

Designed experiment for testing the whole rope and computer modeling method is suitable for practical purposes in industrial practice. It is necessary to keep in mind that the safety of a wire rope is negatively affected by many operating factors. Not only the rope construction but also pulley diameter, rope lubrication, suitable groove shape, rope load, corrosion plays an import role.

\section{References}

Bussolati, F., Allix, O., Guidault, P., Guiton, M. and Poirette, Y. (2018). Toward a two-scale modeling of spiral strand wire rope for floating offshore wind turbine to predict fatigue damages: possibilities and difficulties in using a legacy code. Contact Mechanics International Symposium 2018, Biella.

Benson, D. J. and Hallquist, J. O. (1990). A single surface-contact algorithm for the post-buckling analyses of shell structures. Computer Methods in Applied Mechanics and Engineering, 78(2).

Cech, R., Horyl, P. and Marsalek, P. (2016). Modelling of two-seat connection to the frame of rail wagon in terms of resistance at impact test. Strojnicky Casopis, 66(2).

Chang, X. D., Peng, Y. X., Zhu, Z. C., Gong, X. S., Yu, Z. F., Mi, Z. T. and Xu, C. M. (2019). Breaking failure analysis and finite element simulation of wear-out winding hoist wire rope. Engineering Failure Analysis, 95.

Chen, Y., P., Meng, F. M. and Gong, X. S. (2017). Study on performance of bended spiral strand with interwire frictional contact. International Journal of Mechanical Sciences, 128.

Costello G. A. (1997). Theory of Wire Rope. Springer, New York.

Fontanari, V., Benedetti, M. and Monelli, B. D. (2015). Elasto-plastic behavior of a Warrington-Seale rope: Experimental analysis and finite element modeling. Engineering Structures, 82.

Foti, F. and di Roseto, A. D. (2016). Analytical and finite element modelling of the elastic-plastic behaviour of metallic strands under axial-torsional loads. International Journal of Mechanical Sciences, 115.

Ghoreishi, S. R., Messager, T., Cartraud, P. and Davies, P. (2007). Validity and limitations of linear analytical models for steel wire strands under axial loading, using a 3D FE model. International Journal of Mechanical Sciences, 49(11).

Horyl, P., Marsalek, P., Snuparek, R. and Paczesniowski, K. (2016). Total load-bearing capacity of yielding steel arch supports. Rock Mechanics and Rock Engineering: From the Past to the Future, Cappadocia.

Horyl, P., Snuparek, R. and Marsalek, P. (2014). Behaviour of frictional joints in steel arch yielding supports. Archives of Mining Sciences, 59(3).

Horyl, P., Snuparek, R., Marsalek, P. and Paczesniowski, K. (2017). Simulation of laboratory tests of steel arch support. Archives of Mining Sciences, 62(1).

Horyl, P., Snuparek, R., Marsalek, P., Poruba, Z. and Paczesniowski, K. (2019). Parametric studies of total loadbearing capacity of steel arch supports. Acta Montanistica Slovaca, 24(3).

Ivanco, V., Kmet, S. and Fedorko, G. (2016). Finite element simulation of creep of spiral strands. Engineering Structures, 117.

Jiang, W. G., Henshall, J. L. and Walton, J. M. (2000). Concise finite element model for three-layered straight wire rope strand. International Journal of Mechanical Sciences, 42(1).

Judge, R., Yang, Z., Jones, S. W. and Beattie, G. (2012). Full 3D finite element modelling of spiral strand cables. Construction and Building Materials, 35.

Klemenc, M., Markopoulos, A. and Marsalek, P. (2017). Analysing of critical force effect of aircraft seat belt using truss elements. International Conference of Numerical Analysis and Applied Mathematics 2016, Rhodes.

Marsalek, P. and Horyl, P. (2017). Modelling of bolted connection with flexible yokes used in mining industry. International Conference of Numerical Analysis and Applied Mathematics 2016, Rhodes.

Marsalek, P., Horyl, P., Karasek, T. and Ferfecki, P. (2017). Influence of seat pitch on passenger injury criteria in regional railway traffic. International Conference of Numerical Analysis and Applied Mathematics 2016, Rhodes.

Molnar, V., Fedorko, G., Kresak, J., Peterka, P. and Fabianova, J. (2017). The influence of corrosion on the life of steel ropes and prediction of their decommissioning. Engineering Failure Analysis, 74.

Nawrocki, A. and Labrosse, M. (2000). Finite element model for simple straight wire rope strands. Computers and Structures, 77(4). 
Pistora, J., Lesnak, M., Valicek, J., Harnicarová, M. and Vrabko, V. (2019). Magnetic Field Distribution Around Magnetized Steel Ropes and Its Modulation by Rope Defects. Engineering Design Applications, 72.

Pistora, J., Lesnak, M., Vlasin, O. and Cada, M. (2010). Surface plasmon resonance sensor with magneto-optical structure. Optica Applicata, 40(4).

Song, B., Wang, H., Cui, W., Zhang, J. and Liu, H. (2019). Dynamic simulation and optimization of clamping mechanism of online tension testing machine for wire ropes. Engineering Failure Analysis, 95.

Standard CSN 024313 (2004). Ocelova lana - Ocelova lana jednopramenna, 37 dratu - Rozmery (in Czech).

Standard CSN EN 12385-4 (2008). Ocelova dratena lana - Bezpecnost - Cast 4: Pramenna lana pro vseobecne zdvihaci ucely (in Czech).

Standard DIN 3054 (1972). Drahtseile aus Stahldrahten, Spiralseil 1×37 (in Deutch).

Stanova, E., Fedorko, G., Fabian, M. and Kmet, S. (2011). Computer modelling of wire strands and ropes Part I: Theory and computer implementation. Advances in Engineering Software, 42(6).

Straka, M., Rosova, A., Lenort, R., Besta, P. and Saderova, J. (2018). Principles of computer simulation design fot the needs of improvement of the raw materials combined transport system. Acta Montanistica Slovaca, $23(2)$.

Sun, J. F., Wang, G. L. and Zhang, H. O. (2005). Elasto-plastic contact problem of laying wire rope using FE analysis. International Journal of Advanced Manufacturing Technology, 26(1-2).

Usabiaga, H. and Pagalday, J. M. (2008). Analytical procedure for modelling recursively and wire by wire stranded ropes subjected to traction and torsion loads. International Journal of Solids and Structures, $45(21)$.

Utting, W. S. and Jones, N. (1987). The response of wire rope strands to axial tensile loads-Part I. Experimental results and theoretical predictions. International Journal of Mechanical Sciences, 29(9).

Utting, W. S. and Jones, N. (1987). The response of wire rope strands to axial tensile loads-Part II. Comparison of experimental results and theoretical predictions. International Journal of Mechanical Sciences 29(9).

Velinsky, S. A. (1985). General non-linear theory for complex wire rope. International Journal of Mechanical Sciences, 27(7-8).

Vlcek, J., Lesnak, M., Pistora, J. and Zivotsky O. (2013). Magneto-optical sensing of magnetic field. Optics Communications, 286.

Yu, Y. J., Chen, Z. H., Liu, H. B. and Wang, X. D. (2014). Finite element study of behavior and interface force conditions of seven-wire strand under axial and lateral loading. Construction and Buckling Materials, 66.

Wang, X. Y., Meng, X. B., Wang, J. X., Sun, Y. H. and Gao, K. (2015). Mathematical modeling and geometric analysis for wire rope strands. Applied Mathematical Modelling, 39(3-4). 